\title{
HSR 2020: a call for health systems research in the Eastern Mediter- ranean Region
}

Faraz Khalid, ${ }^{1}$ Muhammad Usman Khan, ${ }^{2}$ Aya Thabet ${ }^{1}$ and Ahmed Mandil ${ }^{1}$

${ }^{1}$ World Health Organization Regional Office for the Eastern Mediterranean, Cairo, Egypt. ${ }^{2}$ Public health consultant, Pakistan. (Correspondence to: Faraz Khalid: khalidf@who.int).

Khalid F; Khan MO; Thabet A; Mandil A. HSR 2020: a wake-up call for health systems research in the Eastern Mediterranean Region. East Mediterr Health J. 2019;25(10):760-762 https://doi.org/10.26719/emhj.19.083

Received: 10/07/19; accepted 29/09/19

Copyright (C) World Health Organization (WHO) 2019. Some rights reserved. This work is available under the CC BY-NC-SA 3.0 IGO license (https:// creativecommons.org/licenses/by-nc-sa/3.0/igo).

The call for abstracts for the Health Systems Research Symposium 2020 (1) was recently announced; the theme "Re-imagining health systems for a better health and social justice" looks bold and ambitious. HSR2020 will be the sixth global symposium on health systems research and for the first time will be hosted in the Eastern Mediterranean Region (EMR) (2). The symposium is scheduled to take place in Dubai, United Arab Emirates, during 8-12 November 2020. The last five global symposia on health systems research (3) were hosted in Africa, Americas, Europe and Western Pacific regions.

The Eastern Mediterranean Region as a host for HSR2020 is deeply symbolic and timely. It is symbolic because of the rich history and heritage of the Region, as a key player in the development of the field of public health and medicine $(4,5)$, although this part of its history is often either obfuscated or not adequately highlighted. It is timely because of the clear relevance between the topics selected for discussion in HSR2020 (1) and the myriad challenges faced by the Region, including progress towards Universal Health Coverage and Sustainable Development Goals (SDGs).

Of the six countries that have been declared to be in a state of Grade 3 Emergency globally, three (Iraq, Syrian Arab Republic and Yemen) are from the Region (6). More than half of the people in need of aid (4) across the world, of all forms including health care, are from the EMR. This is in part due to the destruction of health care delivery systems and infrastructure owing to conflict, but partly due to poor planning resulting in inadequate health systems for tackling any such contingency. Insufficient political will remain a constant hurdle to achieving SDG 3. Political stability and absence of violence/terrorism index (7) reveals that several countries in EMR continue to be vulnerable. These challenges present the perfect opportunity for leveraging and bringing to the forum voices that work either within or with the political structures.

From an environmental perspective, climate change is posing multiple threats to the Region (8). These threats, particularly in terms of influence of climate change on health, are emanating from multiple meteorological and natural phenomena, including water scarcity, heat waves, dust storms, droughts, crop failures, rising temperatures and flood damage to health infrastructure as well as residential areas. A regional trend analysis has depicted that EMR countries are facing adverse health impacts of climate change. This has translated into an increase in "waterborne diseases, spread of vector-borne diseases, undernutrition, drowning, mortality and morbidity during heat waves, allergic reactions, pulmonary diseases due to dust storms and heat waves as well as cardiovascular and respiratory illnesses and psychosocial stress" (9). Indirectly, climate change can impact health through creating socio-economic conditions that can result in limited avenues for livelihood and augment conflicts by increasing resource scarcity. This threat is ever more menacing given the already fragile social and political states of various countries in the Region.

Since the establishment of World Health Organization's Regional Centre for Environmental Health Action, the research and awareness on the linkages between climate change and health have improved, but there is still a long way to go (10). On the technological front, EMR presents a wide spectrum mosaic (geopolitically and socioeconomically); on the one hand, some Gulf countries are being touted as possible global leaders in terms of deploying $5 \mathrm{G}$ telecommunication (11), while on the other hand most countries in the Region do not have adequate civil registration, vital statistics and population-based surveillance systems (11). This unexplored domain i.e. technological innovation, especially in terms of health, offers a great avenue for research and policy dialogue.

Unfortunately, the EMR has been extremely underrepresented at the previous HSR symposia. The region is comprised of 22 countries and is home to nearly 645 million people - about $9 \%$ of the world's population (12), yet the highest representation for the Region was $4 \%$, back in 2010 (Figure 1).

This should not come as a surprise given the comparatively limited research being done in the Region in general, and the dearth of health policy and health systems research in particular (13). This poor research output can be understood in the context of various challenges being faced by EMR countries. There is limited national, regional and international funding for health research. International and regional funding 


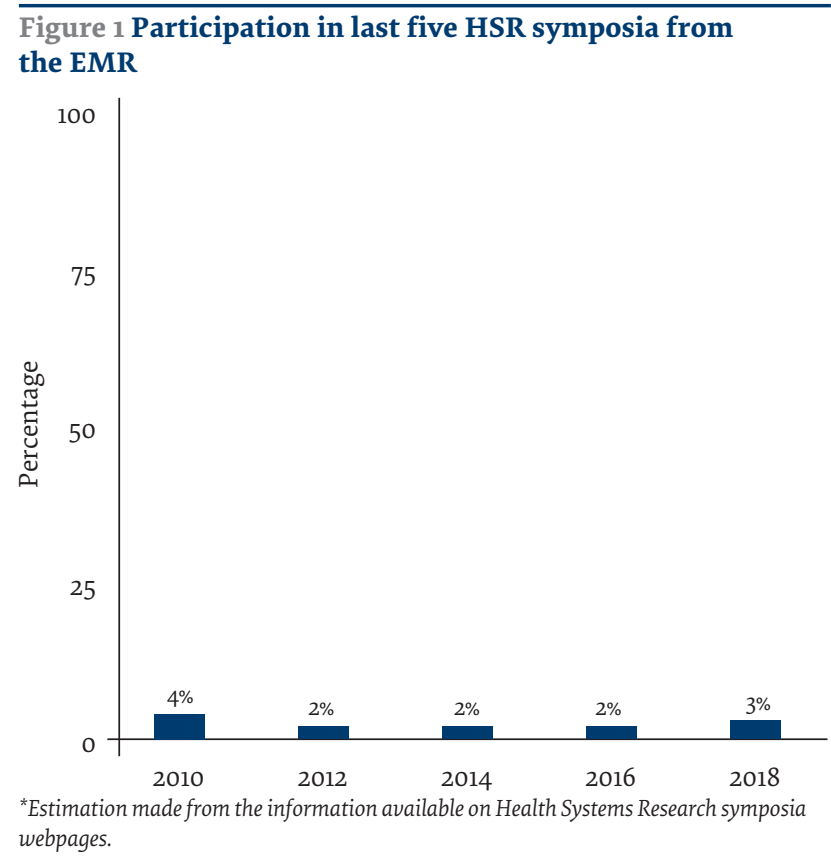

is perhaps limited due to weak institutional capacity to attract funds, while limited national funding may be due to lack of awareness among policy-makers, regarding the immense importance of health systems research, and hence evidence-based health-policy-making. Several countries in the Region also lack national health strategies and policies. In other cases, national research policy is not present (14).

Another critical factor has been the immense brain drain which has limited the research capacity and output of the Region. The Eastern Mediterranean Region has also lagged in terms of Knowledge Transfer and Exchange (KTE). Less than one quarter of research (15) was transformed into policy briefs or advocacy messages that had specified tangible actions. Policy-makers are rarely part of the research process and the research exists in a non-receptive environment where political or socially sensitive findings impede uptake. Although some institutions exist in the Region to support knowledge translation and dissemination, as those hosted by Lebanon, Islamic Republic of Iran and Saudi Arabia (1619), yet much more needs to be developed and fostered.

HSR 2020 offers a landmark opportunity for the EMR countries to make a concerted effort in bolstering health systems and policy research. It is a unique opportunity for public and academic institutions, think-tanks, private sector, professional societies, development partners as well as grass-roots non-governmental organizations to open and revive discussions around the importance of health systems research and press for evidence-based policy formulation. Such stakeholders could galvanize their research strength and make the symposium topics an integral part of their research agenda for the coming year.

Simultaneously, greater demand for funding from both public and private entities should be made. Governments and development partners in the Region can play an instrumental role in providing technical and financial support for advocacy and awareness generation about the symposium, as well as capacity building and effective participation of health researchers, practitioners and policy-makers, especially operating in the EMR, in this unique symposium.

Lastly, other than the host partners (Mohammed bin Rashid School of Government, Dubai, United Arab Emirates, and Knowledge to Policy (K2P) Center at American University of Beirut, Beirut, Lebanon), more collaborations and partnerships among Health Systems Global, academic/research institutions, ministries of health, and development partners in the Region are required to stir the momentum for the activities leading up to the symposium and their continuity afterwards.

\section{References}

1. Health Systems Research Symposium 2020: Call for Abstracts. Health Systems Global, 12 September 2019. (https://hsr2020. healthsystemsresearch.org/abstracts).

2. Eastern Mediterranean Region to Host the Sixth Global Symposium on Health Systems Research in 2020. Health Systems Global, 15 May 2018, (http://www.healthsystemsglobal.org/blog/285/Eastern-Mediterranean-Region-to-host-the-Sixth-Global-Symposium-on-Health-Systems-Research-in-2020.html).

3. Global Symposium on Health Systems Research. Health Systems Global, (http://www.healthsystemsglobal.org/globalsymposia/).

4. Shetty P. Arabic roots of modern medicine. Lancet. 2011;378:19-20. https://doi.org/10.1016/So140-6736(11)61004-0.

5. Kayali G. The forgotten history of pre-modern epidemiology: contribution of Ibn An-Nafis in the Islamic golden era. East Mediterranean Health J. 2017;23(12):854-857.

6. World Health Organization Regional Office for the Eastern Mediterranean (WHO/EMRO). WHO Health Emergencies - Countries in Crisis. Cairo: WHO/EMRO; 2018 (https://www.emro.who.int/eha/countries-in-crisis/index.html).

7. Land Portal. Political stability and absence of violence/terrorism (Index). Amersfoort: Land Portal Foundation; 2019 (https://landportal.org/book/indicator/fao-21032-6125).

8. Intergovernmental Panel on Climate Change (IPCC). AR5 Synthesis Report: Climate Change 2014. Geneva: IPCC; 2018 (https:// www.ipcc.ch/report/ar5/syr/).

9. Khader YS, Abdelrahman M, Abdo N, Al-Sharif M, Elbetieha A, Bakir H, et al. Climate change and health in the Eastern Mediterranean Countries: a systematic review. Rev Environ Health. 2015;30(3):163-81. 
10. World Health Organization Regional Office for the Eastern Mediterranean (WHO/EMRO). Regional Center for Environmental Health Action. Cairo: WHO/EMRO; 2018 (http://www.emro.who.int/entity/ceha/index.html).

11. Radcliffe D. Middle East tech: what does 2019 have in store?" ZDNet, ZDNet, 16 January 2019 (https://www.zdnet.com/article/ middle-east-tech-what-does-2019-have-in-store/).

12. World Health Organization Regional Office for the Eastern Mediterranean (WHO/EMRO). Roadmap of WHO's work for the Eastern Mediterranean Region, 2017-2021. Cairo: WHO/EMRO; 2017 (http://applications.emro.who.int/docs/EMROPUB_2017_19695_EN.pdf?ua=1).

13. Mandil A, El-Jardali F, El-Feky S, Nour M, Al-Abbar M, Bou-Karroum L. Health research institutional mapping: an Eastern Mediterranean Regional perspective. East Mediterranean Health J. 2018;24(2):189-197.

14. Kennedy A, Khoja TA, Abou-Zeid AH, Ghannem H, IJsselmuiden C, WHO-EMRO/COHRED/GCC NHRS Collaborative Group. National Health Research System Mapping in 10 Eastern Mediterranean Countries. East Mediterr Health J. 2008 MayJun;14(3):502-17.

15. El-Jardali F Lavis JN, Ataya N, Jamal D, Ammar W, Raouf S. Use of health systems and policy research evidence in the health policymaking in eastern Mediterranean countries: views and practices of researchers. BMC Health Services Research 2012;12(200).

16. American University of Beirut (AUB) Knowledge to Policy Center (K2P). The call for abstracts is now open. Beirut: AUB; 2019 (https://www.aub.edu.lb/k2p/Pages/default.aspx).

17. Tehran University of Health Sciences (TUMS), Knowledge Utilization Research Center (KURC). Homepage. Tehran: TUMS; 2019 (http://kurc.tums.ac.ir/en/home/).

18. National Institute of Health Research (NIHR), Ministry of Health and Medical Education. Homepage. Tehran: NIHR; (http:// nihr.tums.ac.ir/En/Home?AspxAutoDetectCookieSupport=1).

19. King Saud University. Shaikh Bahamadan Research Chair on Evidence-Based Healthcare and Knowledge Translation. Riyadh: King Saud University; 2019 (https://ebhc.ksu.edu.sa/en/node/1118). 